\title{
USO DE DIFERENTES POPULAÇÕES NA CULTURA DO MILHO PLANTADO EM SEGUNDA SAFRA NA REGIÃO DE MINEIROS, ESTADO DE GOIÁS
}

\author{
ALMEIDA JÚNIOR Joaquim Júlio ${ }^{1}$ \\ FERREIRA Jamil Davi ${ }^{2}$ \\ SMILJANIC Katya Bonfim Ataides ${ }^{3}$ \\ MATOS Francisco Solano Araújo ${ }^{4}$ \\ SIMON Gustavo André \\ PEROZINI Alexandre Caetano ${ }^{6}$ \\ MIRANDA Beatriz Campos ${ }^{7}$ \\ SILVA Victor Júlio Almeida ${ }^{8}$
}

\begin{abstract}
RESUMO: Várias pesquisas a respeito da densidade de plantio, ou estande, definida como número de plantas por unidade de área, têm confirmado papel importante no rendimento de uma lavoura de milho, uma vez que variações têm influência na produtividade final da cultura. Este trabalho teve por objetivo avaliar a biometria da cultura do milho e sua produtividade final em diferentes populações de plantas por metro. $\mathrm{O}$ experimento foi implantado na região de Mineiros, no Estado de Goiás, apresentando coordenadas geográficas aproximadas de $17^{\circ} 58^{\prime} \mathrm{S}$ de latitude e $45^{\circ} 22^{\prime}$ W de longitude e com 845 m de altitude. Foi conduzido no ano agrícola de 2016 e 2017 pelo Núcleo de Estudo e Pesquisa em Fitotecnia que utilizou o híbrido de milho DKB 390 PRO e os tratamentos de 44.444, 88.888, 133.332, 177.776 e 222.222 plantas por hectare respectivamente, com quatro linhas de quatro metros de comprimento por parcelas e área útil de duas linhas centrais com um metro de descarte nas extremidades e espaçamento entre linhas de $45 \mathrm{~cm}$. O delineamento experimental foi em blocos casualizados, com esquema fatorial $5 \mathrm{x} 1$ com quatro repetições. Foi avaliada a biometria da planta nos seguintes parâmetros: altura de planta, altura de inserção de primeira espiga, diâmetro do colmo, população de planta por hectare e número de plantas ha ${ }^{-1}$. A resposta entre a relação população e produtividade no trabalho realizado com a cultura do milho em segunda safra de 2016/2017mostrou que a produtividade é afetada conforme ocorre o aumento da população de plantas por hectare, sendo que, resultado similar foi obtido com a repetição do trabalho realizado na segunda safra de 2017/2018.
\end{abstract}

Palavras-Chave: Distribuição espacial, Estande, Zea mays.

SUMMARY: Several researches on planting density, or stand, defined as number of plants per unit area, have confirmed an important role in the yield of a maize crop, since variations influence the final yield of the crop. The objective of this work was to evaluate the biometry of the corn crop and its final yield in different plant populations per meter. The experiment was carried out in the region of Mineiros, in the state of Goiás, with approximate geographical coordinates of $17^{\circ} 58$ 'S latitude and $45^{\circ} 22^{\prime} \mathrm{W}$ longitude and $845 \mathrm{~m}$ altitude. It was conducted in the agricultural year 2016 and 2017 by the Nucleus of Study and Research in Plant Science that used the corn hybrid DKB 390 PRO and the treatments of 44,444, 88,888, 133,332, 177,776 and 222,222 plants per hectare respectively, with four lines of four meters length per plot and area of two central lines with one meter of discard at the ends and spacing between lines of $45 \mathrm{~cm}$. The experimental design was in randomized blocks, with a $5 \times 1$ factorial scheme with four replications. The biometrics of the plant were evaluated in the following parameters: plant height, first ear insertion height, stem diameter, plant population per hectare and number of plants ha-1. The response between the population and productivity ratio in the work performed with maize in the second crop of 2016/2017 showed that productivity is affected as the population of plants per hectare increases, and a similar result was obtained by repeating the work carried out in the second crop of 2017/2018.

Keywords: Spatial distribution, Booth, Zea mays.

\footnotetext{
${ }^{1}$ Pós-Doutor em Fitotecnia (Produção Vegetal) pela Universidade de Coimbra - Portugal. Professor Titular da UniFIMES - Centro Universidade de Mineiros

${ }^{2}$ Acadêmico do curso de Agronomia da UniFimes

${ }^{3}$ Professora Adjunta na UniFimes; Bióloga; Mestre em Botânica

${ }^{4}$ Professor Adjunto na UniFimes; Pesquisador da EMATER- Jataí; Engenheiro Agrônomo; Mestre em Sanidade e Fitotecnia.

${ }^{5}$ Professor Titular da UniRV- Universidade de Rio Verde; Doutor em Genética e Melhoramento de plantas

${ }^{6}$ IFMT Campus São Vicente. Departamento de Engenharia Rural e Fitotecnia.

${ }^{7}$ Acadêmica do curso de Engenharia Florestal.

${ }^{8}$ Acadêmico do curso de Direito da FAR - Faculdade Almeida Rodrigues - Rio Verde, Goiás
} 


\section{INTRODUÇÃO}

O milho é uma planta tropical e como tal, para apresentar a produtividade esperada necessita de água e calor em seu ciclo de vida. A temperatura é importante para manter as funções fisiológicas como a fotossíntese, respiração e transpiração. Já a disponibilidade água influencia diretamente o crescimento em função da expansão e multiplicação de células, desenvolvimento e o transporte tanto de sais minerais quanto dos produtos da fotossíntese (FANCELLI, 2015).

O milho (Zea mays L.) é uma cultura importante para o mundo em função das várias formas na sua utilização, na proporção de áreas plantadas e da grande capacidade de produção. $\mathrm{O}$ Brasil é o segundo maior exportador do cereal e o terceiro maior produtor em nível mundial, produzindo em torno de 351 milhões de toneladas considerando a safra 2016/2017 e 2017/2018, com uma média de produção superior a 5,5 t ha-1. Estes resultados podem ser atribuídos aos avanços das cultivares, condições climáticas e a fertilidade do solo (CONAB, 2017).

O Brasil é o terceiro maior produtor mundial de milho que é produzido praticamente em todas as regiões do país. A cultura apresenta grande importância econômica e social além de ser considerada uma das principais espécies de cereais utilizadas no Brasil (CONAB, 2017).

Na safra 2016/2017 e 2017/2018 foram cultivados cerca de 16.772 milhões de hectares com produção de aproximadamente 88.969 milhões de toneladas e produtividade média de 5.305 $\mathrm{kg} \mathrm{ha}^{-1}$ de grão (CONAB, 2017).

De acordo com CONAB (2018) a produção do milho é avaliada pelo número de espigas por hectares influenciados pelo número de plantas, número de grãos por espiga e o peso do grão. O milho apresenta pouca elasticidade de crescimento quando comparada à outras espécies da família Poaceae, quase nunca perfilha efetivamente não tem aptidão de expansão foliar (HANASHIRO et al., 2015). Os híbridos atuais não perfilham, usualmente produzem somente uma espiga por planta e não têm a capacidade de compensar casuais falhas de emergência na lavoura (SANTOS et al., 2012). Para que se obtenham elevados rendimentos de grãos, recomenda-se elevar ao máximo a interceptação da radiação solar, opção apropriada do arranjo de plantas. A cooptação entre melhoria do arranjo de plantas e do aumento do rendimento de grãos de milho tem sido citada na literatura (SILVA; AZEVEDO, 2016).

Para Pinotti (2013) muitas pesquisas relacionadas a densidades de plantas demonstraram que as populações de plantas que permitem uma melhor produtividade podem variar de $30.000 \mathrm{a}$ 90.000 plantas ha $^{-1}$, em função de fatores como época de semeadura, adubação, regime de chuvas e o espaçamento entre linhas. 
Ao conduzir experimento com intuito de verificar desempenho de dois cultivares de milho, semeadas em quatro diferentes populações sendo, 30.000, 45.000, 60.000 e 75.000 plantas ha $^{-1}$ e três épocas de semeadura Pinotti (2013) registrou que na medida em que a população aumentou houve também aumento no índice de altura de inserção de espiga, relação entre altura de espiga e altura e diâmetro de colmo. Quanto a avaliação da espiga, o aumento da população de plantas levou ao aumento do número de espigas e número de grãos por hectare (PINOTTI, 2013).

Oliveira (2014) avaliou a produtividade do milho em diferentes populações de plantas (70.000, 85.000, 95.000, 100.000, 105.000, 111.000, 120.000 e 151.000 plantas/ha ${ }^{1}$ ) encontrando diferenças significativas em todos os parâmetros avaliados exceto diâmetro de colmo e concluiu que é possível aumentar o rendimento de grãos com a variação da população de plantas.

O arranjo de plantas pode-se manusear por meio de modificações na população de plantas, no espaçamento entre linhas e na distribuição de plantas na linha, em que as variações na distância entre plantas na linha e nas entrelinhas atribuem os diferentes arranjos espaciais na lavoura (ALMEIDA JÚNIOR et al., 2017).

O mais eficiente arranjo é aquele que propicia distribuição uniforme de plantas por área, ou seja, equidistante entre plantas, permitindo melhor utilização de luz, água e nutrientes além de outros fatores que influenciam no desenvolvimento (ALMEIDA JÚNIOR et al., 2017).

De acordo com Bullock et al. (1988) os exemplos de distribuição mais eficientes ocorrem em virtude do uso de espaçamentos reduzidos, que podem aumentar a taxa de crescimento inicial da cultura, levando a uma melhor interceptação e eficiência de uso da radiação solar, proporcionando um maior rendimento de grãos devido ao acréscimo na produção fotossintética final.

Assim, a escolha do arranjo de plantas ideal é de máxima importância para aumentar o rendimento de grãos de milho, porque influencia diretamente na interceptação de radiação solar, que é o principal fator para a produtividade de grãos, desde que outros fatores como água e nutrientes estejam disponíveis (BRACHTVOGEL et al., 2012).

Dentre as formas existentes de manejo do arranjo espacial, a população de plantas é a que mais influência na produtividade de grãos de milho (ALMEIDA JÚNIOR et al., 2017).

Assim, este trabalho teve por objetivo avaliar a biometria da cultura do milho e sua produtividade final com diferentes populações de plantas por metro implantado por duas safras na região de Mineiros, no Estado de Goiás. 


\section{MATERIAL E MÉTODO}

O experimento foi conduzido na segunda safra nos anos agrícolas de 2016/2017 e 2017/2018, em área experimental do Núcleo de Estudo e Pesquisa em Fitotecnia, município de Mineiros, Estado de Goiás. A localidade apresenta como coordenadas geográficas aproximadas, $17^{\circ} 58^{\prime} \mathrm{S}$ de latitude e $45^{\circ} 22^{\prime} \mathrm{W}$ de longitude e $845 \mathrm{~m}$ de altitude.

O clima predominante da região, conforme classificação de Köppen (2013) é do tipo Aw, definido como tropical úmido com estação chuvosa no verão e seca no inverno. A precipitação pluvial média anual é de $1.830 \mathrm{~mm}$, com temperatura média anual de aproximadamente $25^{\circ} \mathrm{C}$ e umidade relativa do ar média anual de $66 \%$ (Figura 1). O período chuvoso se estende de outubro a março, sendo que os meses de dezembro, janeiro e fevereiro constituem o trimestre mais chuvoso, e o trimestre mais seco corresponde aos meses de junho, julho e agosto (média de 27 $\mathrm{mm})$.

Figura 1. Valores de precipitação pluvial $(\mathrm{mm})$ médias mensais, umidade relativa (\%) médias mensais, temperaturas $\left({ }^{\circ} \mathrm{C}\right)$ médias mensais, acumulou na segunda safra 2016/2017 e 2017/2018 na área experimental do Núcleo de Estudo e Pesquisa em Fitotecnia. Município de Mineiros/GO. 2018 .

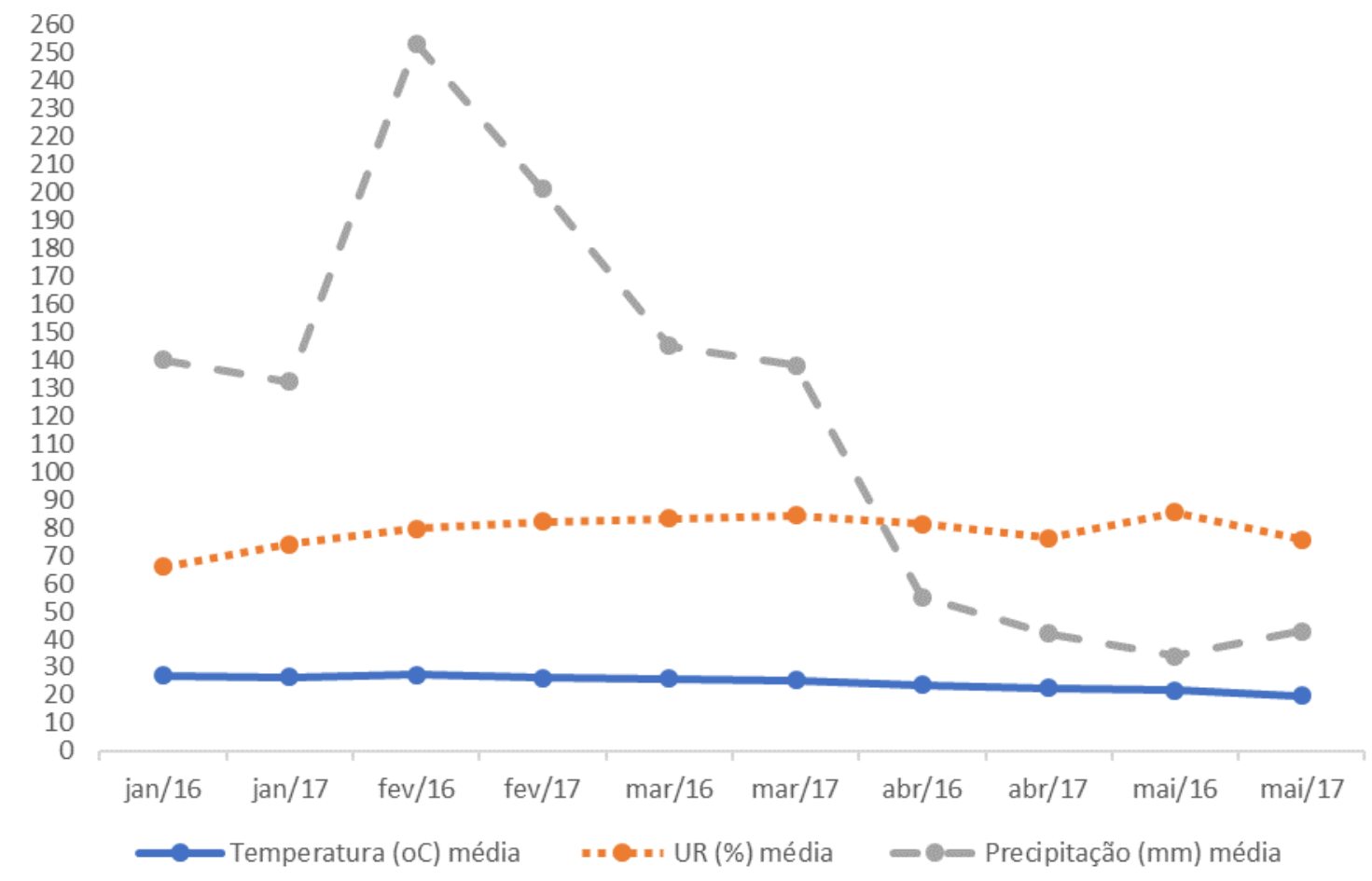

Fonte: Posto Agrometerológico da UNIFIMES, 2018.

O solo predominante na área conforme a nova denominação do Sistema Brasileiro de Classificação de Solos (EMBRAPA, 2013) é o Neossolo Quartzarênico e de textura arenosa, o qual foi originalmente ocupado por vegetação de Cerrado e vem sendo explorado por culturas anuais há mais de 15 anos. 
O delineamento experimental foi em blocos casualizados em esquema fatorial $5 \times 1$ e quatro repetições. Cada parcela experimental foi constituída de quatro linhas de quatro metros de comprimento com área útil de duas linhas de dois metros de comprimento e espaçamento de 45 cm entre linhas e espaçamento entre blocos de 2,0 metros de comprimentos.

A cultivar utilizada foi o híbrido de milho DKB 390 PRO e os tratamentos foram as seguintes populações: T1: $44.444 \mathrm{ha}^{-1}$; T2: $88.888 \mathrm{ha}^{-1}$; T3: $133.332 \mathrm{ha}^{-1}$; T4: $177.776 \mathrm{ha}^{-1}$ e T5: 222.222 plantas por hectare com adubação mineral de $300 \mathrm{~kg} \mathrm{ha}^{-1}$ de acordo com as características químicas do solo da área experimental e duas coberturas nitrogenadas.

A avaliação da população foi feita 30 dias após germinação (DAG), estudos da biometria (parte aérea) foi realizado no estádio fenológico R3 (grãos pastosos) e produtividade em sacas por hectare no estádio fenológico R6 (maturação fisiológica da planta).

Os atributos do solo foram avaliados antes da implantação do projeto de pesquisa para conhecer as características químicas da área experimental. Foram determinados os atributos químicos do solo (pH P, K, Ca, Mg, H+Al, Al, S.B, V (\%) em M.O.) camadas de 0,0 a 0,20 e de 0,20 a 0,40 metros de profundidade, seguindo a metodologia proposta por Raij e Quaggio (1983). As análises foram feitas no Laboratório de Fertilidade do Solo da Instituição e estão expressas na Tabela 1.

Tabela 1. Resultados obtidos na análise química do solo, coletada na área experimental do Núcleo de Estudo e Pesquisa em Fitotecnia. amostrada antes do plantio do milho DKB 390 PRO. Município de Mineiro/GO. 2018.

\begin{tabular}{|c|c|c|c|c|c|c|c|c|c|c|c|c|}
\hline \multirow{4}{*}{$\begin{array}{l}\bar{\sigma} \\
\delta \\
\delta \\
\delta \\
\delta \\
0\end{array}$} & \multirow{3}{*}{$\begin{array}{l}\text { Profundidade } \\
\qquad(\mathrm{cm}) \\
0-20\end{array}$} & $\mathrm{pH}$ & $\mathrm{P}(\mathrm{Mel})$ & $\mathrm{K}^{+}$ & $\mathrm{Ca}$ & $\mathrm{Mg}$ & $\mathrm{Al}$ & $\mathrm{H}+\mathrm{Al}$ & S.B. & CTC & $\mathrm{V}$ & M.O. \\
\hline & & $\mathrm{CaCl}_{2}$ & $\mathrm{mg} \mathrm{dm}^{-3}$ & \multicolumn{7}{|c|}{ mmolc $\mathrm{dm}^{-3}$} & $\%$ & $\mathrm{~g} \mathrm{dm}^{-3}$ \\
\hline & & 4,9 & 7,0 & 1,6 & 18 & 10 & 0 & 31 & 29,6 & 60,8 & 49,05 & 22 \\
\hline & $20-40$ & 4,9 & 6,1 & 1 & 5 & 3 & 0 & 29 & 9 & 38 & 23,76 & 18 \\
\hline & $\begin{array}{l}\text { Profundidade } \\
(\mathrm{cm})\end{array}$ & $\mathrm{pH}$ & $\mathrm{P}(\mathrm{Mel})$ & $\mathrm{K}+$ & $\mathrm{Ca}$ & $\mathrm{Mg}$ & $\mathrm{Al}$ & $\mathrm{H}+\mathrm{Al}$ & S.B. & CTC & $\mathrm{V}$ & M.O. \\
\hline \multirow{3}{*}{$\frac{\substack{\infty \\
ٍ}}{\frac{N}{0}}$} & & $\mathrm{CaCl}_{2}$ & $\mathrm{mg} \mathrm{dm}^{-3}$ & \multicolumn{7}{|c|}{ mmolc $\mathrm{dm}^{-3}$} & $\%$ & $\mathrm{~g} \mathrm{dm}^{-3}$ \\
\hline & $0-20$ & 4,5 & 8,0 & 1,4 & 18 & 9 & 0 & 30 & 28,4 & 70,8 & 55,05 & 26 \\
\hline & $20-40$ & 4,4 & 6,8 & 1,2 & 8 & 4 & 0 & 27 & 13,2 & 43 & 27,67 & 21 \\
\hline
\end{tabular}

\section{Fonte: Dados da pesquisa, 2018.}

Foi avaliada a biometria das plantas utilizando como parâmetros: altura de planta, altura de inserção de primeira espiga, diâmetro do colmo, população de planta por hectare e número de plantas $\mathrm{ha}^{-1}$. Para estas avaliações foram contados o número de plantas nas duas linhas centrais com descarte de um metro nas extremidades. Para avaliação da produção $\left(\mathrm{kg} \mathrm{ha}^{-1}\right)$ foram coletadas e pesadas as espigas das plantas na área útil de cada parcela com umidade corrigida para $14 \%$. 
Os dados foram analisados pelo programa Assistat, proposto por Silva e Azevedo. (2016). Os dados obtidos foram submetidos à análise de variância, sendo as médias comparadas pelo teste $\mathrm{t}$, quando detectada significância para a ANOVA a $\mathrm{p}=0,05$ de probabilidade para a comparação de médias.

\section{RESULTADO E DISCUSSÃO}

Os valores médios para altura de plantas, inserção de primeira espiga e diâmetro de colmo em segunda safra 2016/2017 (Tabela 2) não apresentaram diferenças estatísticas significativa para o híbrido de milho DKB 390 PRO plantado. Em virtude deste material ser um híbrido simples e superprecoce, podemos acreditar que suas características agronômicas não ocorrem grandes variações. Resultado contrário foi encontrado por Barbosa et al. (2010), em que os valores de altura de planta aumentaram em relação ao acréscimo da população simultaneamente, na mesma linha de raciocínio ocorreu para o efeito da inserção de primeira espiga, quando se aumenta a população ocorre um acréscimo e/ou alongamento do colmo assim a inserção da primeira espiga aumenta, o mesmo ocorrendo com diâmetro de colmo.

Para as mesmas variáveis em segunda safra 2017/2018 (Tabela 2) os dados apresentaram diferenças estatísticas significativa para o híbrido de milho DKB 390 PRO plantado, nota-se nos tratamentos T2, T3, T4 e T5 com as médias de 2,06; 2,11; 2,15 e 2,18 respectivamente, não ocorreram diferenças estatísticas significativa entre si, mas já o tratamento T1 com uma média de $2,05 \mathrm{~cm}$ foi o que obteve a menor média. Resultado semelhante foi encontrado por Barbosa et al. (2010), em que os valores de altura de planta aumentaram em relação ao acréscimo da população simultaneamente, o que também ocorreu para o efeito da inserção de primeira espiga, quando se aumenta a população ocorre um acréscimo e/ou alongamento do colmo assim a inserção da primeira espiga aumenta, o mesmo não ocorrendo com diâmetro de colmo. 
Tabela 2. Características biométricas da cultura, altura de plantas, inserção da primeira espiga e diâmetro de colmo do híbrido de milho DKB 390 PRO, em segunda safra 2016 e 2017 na área experimental do Núcleo de Estudo e Pesquisa em Fitotecnia. Município de Mineiros /GO. 2018.

\begin{tabular}{ccccccc}
\hline \multirow{2}{*}{ Tratamentos } & \multicolumn{3}{c}{ Altura } & \multicolumn{2}{c}{ Diâmetro } \\
\cline { 2 - 7 } & $2016 / 2017$ & $2017 / 2018$ & $2016 / 2017$ & $2017 / 2018$ & $2016 / 2017$ & $2017 / 2018$ \\
\cline { 2 - 7 } & $\begin{array}{c}\text { Plantas } \\
(\mathrm{m})\end{array}$ & $\begin{array}{c}\text { Plantas } \\
(\mathrm{m})\end{array}$ & $\begin{array}{c}\text { I. Primeira } \\
\text { Espiga }(\mathrm{m})\end{array}$ & $\begin{array}{c}\text { I. Primeira } \\
\text { Espiga }(\mathrm{m})\end{array}$ & $\begin{array}{c}\text { Colmo } \\
(\mathrm{mm})\end{array}$ & $\begin{array}{c}\text { Colmo } \\
(\mathrm{mm})\end{array}$ \\
\hline T1 & 2,05 & $1,98 \mathrm{~b}$ & 0,91 & $1,01 \mathrm{a}$ & 23,24 & $16,31 \mathrm{a}$ \\
T2 & 2,10 & $2,06 \mathrm{ab}$ & 1,07 & $1,12 \mathrm{ab}$ & 18,72 & $12,13 \mathrm{~b}$ \\
T3 & 2,26 & $2,11 \mathrm{a}$ & 1,14 & $1,19 \mathrm{~b}$ & 18,39 & $11,38 \mathrm{~b}$ \\
T4 & 2,20 & $2,15 \mathrm{a}$ & 1,20 & $1,26 \mathrm{~b}$ & 18,77 & $11,17 \mathrm{~b}$ \\
T5 & 2,31 & $2,18 \mathrm{a}$ & 1,10 & $1,45 \mathrm{ab}$ & 19,60 & $8,54 \mathrm{c}$ \\
\hline CV $(\%)$ & 8,65 & 4,14 & 12,77 & 7,73 & 9,18 & 6,99 \\
\hline DMS & 0,31 & 0,13 & 0,54 & 0,14 & 2,18 & 1,28 \\
\hline
\end{tabular}

*Altura I. Espiga: Altura de Inserção da primeira espiga; CV: Coeficiente de variação.

Fonte: Dados da pesquisa, 2018.

Para os valores médios de população de plantas por hectare, população de plantas por metro e produtividade em quilograma por hectare (Tabela 3) foram observadas diferenças estatísticas para o híbrido de milho DKB 390 PRO plantado nas safras 2016/2017 e 2017/2018 com o acréscimo na população por hectare, ocorreu simultaneamente um decréscimo na produtividade, sendo que a população que obteve a maior média foi o T1 com 54.444 plantas por hectare, e uma média de produtividade na ordem de $8985 \mathrm{~kg}$ por hectare. Em trabalho realizado por Foloni, et al. (2014) trabalhando com diferentes populações de plantas, também ocorreu diferença entre populações testadas.

Resultado diferente foi observado na segunda safra de 2017/2018, onde a melhor produtividade foi encontrada no tratamento T3 com uma média de $10713 \mathrm{~kg}$ hectare. Efeito contrário foi encontrado por Hotz et al. (2015) onde em estudos realizados com uma população de 50.000, 75.000 e 100.000 plantas por hectare não foram encontradas diferenças estatísticas na produtividade, mas ressalta que fica evidente a necessidade de ainda serem realizados estudos na região para fazer alguma afirmação concreta sobre esta prática. Para as variáveis população de planta por hectare e por metro, as médias esperadas foram satisfatória, em virtude de ser um trabalho realizado à campo. 
Tabela 3. Características biométricas da cultura, estande, população de plantas por hectare e população de plantas por metro do híbrido de milho DKB 390 PRO, em segunda safra 2016/2017 e 2017/2018, na área experimental do Núcleo de Estudo e Pesquisa em Fitotecnia. Município de Mineiros/GO. 2018.

\begin{tabular}{ccccccc}
\hline Tratamentos & \multicolumn{3}{c}{ População } & \multicolumn{2}{c}{ Produtividade } \\
\cline { 2 - 7 } & $2016 / 2017$ & $2017 / 2018$ & $2016 / 2017$ & $2017 / 2018$ & $2016 / 2017$ & $2017 / 2018$ \\
\cline { 2 - 7 } & P. ha $^{-1}$ & P. ha $^{-1}$ & P. Metro & P. Metro & Kg ha $^{-1}$ & Kg ha $^{-1}$ \\
\hline T1 & $54444 \mathrm{a}$ & $45111 \mathrm{a}$ & $2,45 \mathrm{a}$ & $2,03 \mathrm{a}$ & $8985 \mathrm{a}$ & $6823 \mathrm{~b}$ \\
T2 & $88888 \mathrm{~b}$ & $83999 \mathrm{~b}$ & $4,00 \mathrm{~b}$ & $3,78 \mathrm{~b}$ & $8040 \mathrm{ab}$ & $9662 \mathrm{a}$ \\
T3 & $132221 \mathrm{c}$ & $127777 \mathrm{c}$ & $5,95 \mathrm{c}$ & $5,75 \mathrm{c}$ & $6570 \mathrm{bc}$ & $10713 \mathrm{a}$ \\
T4 & $178331 \mathrm{~d}$ & $155554 \mathrm{~d}$ & $8,03 \mathrm{~d}$ & $7,00 \mathrm{~d}$ & $6570 \mathrm{bc}$ & $9923 \mathrm{a}$ \\
T5 & $222220 \mathrm{e}$ & $210442 \mathrm{e}$ & $10,00 \mathrm{e}$ & $9,47 \mathrm{e}$ & $6420 \mathrm{c}$ & $9738 \mathrm{a}$ \\
\hline CV $(\%)$ & 9,14 & 9,14 & 9,14 & 5,92 & 8,98 & 16,78 \\
\hline DMS & 0,49 & 0,51 & 1,02 & 0,51 & 1845,17 & 2423,13 \\
\hline
\end{tabular}

*População P. ha ${ }^{-1}$ : População de plantas por hectare; População P. Metro: População de plantas por metro; Produtividade $\mathrm{sc} \mathrm{ha}^{-1}$ : Produtividade em sacas por hectare.

Médias seguidas pela mesma letra na coluna não diferem entre si pelo teste Tukey a $5 \%$ de probabilidade.

Fonte: Dados da pesquisa, 2018.

Verifica-se na Figura 2A com a curva polinomial para variável tecnologica produtividade em $\mathrm{kg}$ por hectare que ocorreu uma queda muito acentuada de produtividade entre os tratamentos T1 e o T3, em que a média de produtividade do tratamento T1 foi de $8985 \mathrm{~kg}$ por hectare e o tratamento T3 foi de $6570 \mathrm{~kg}$ por hectare, estabilizando-se até o tratamento T5 com média de $6420 \mathrm{~kg}$ por hectare. Resultado diferente foi encontrado no experimento realizado na segunda safra de 2017/2018 (Figura 2B) onde a melhor resposta a produtividade foi encontrada no tratamento T3 com uma média de $10713 \mathrm{~kg}$ hectare e posteriormente ocorrendo um decréscimo. Este resultado pode ser justificado em virtude de se plantar na safra de verão anterior ao plantio da segunda safra ter sido feito uma safra de soja, assim promovendo uma melhoria no solo. Esses resultados estão de acordo com Dourado Neto et al. (2003) que relatou que com aumento da população ocorreu redução na produtividade, independentemente dos genótipos e espaçamentos utilizados, resulta no decréscimo da produtividade. Segundo Fancelli e Dourado Neto (2003) a competição por luz em plantios densos resulta em plantas maiores e com menor ganho de massa seca e uma redução na produtividade em sacas por hectare. 
Figura 2. Curva polinomial para variável tecnológica produtividade em sacas por hectare submetida a cinco populações de plantas do híbrido de milho DKB 390 PRO, em segunda safra 2016/2017 (Figura 2A) e 2017/2018 (Figura 2B) na área experimental do Núcleo de Estudo e Pesquisa em Fitotecnia. Município de Mineiros/GO. 2018.

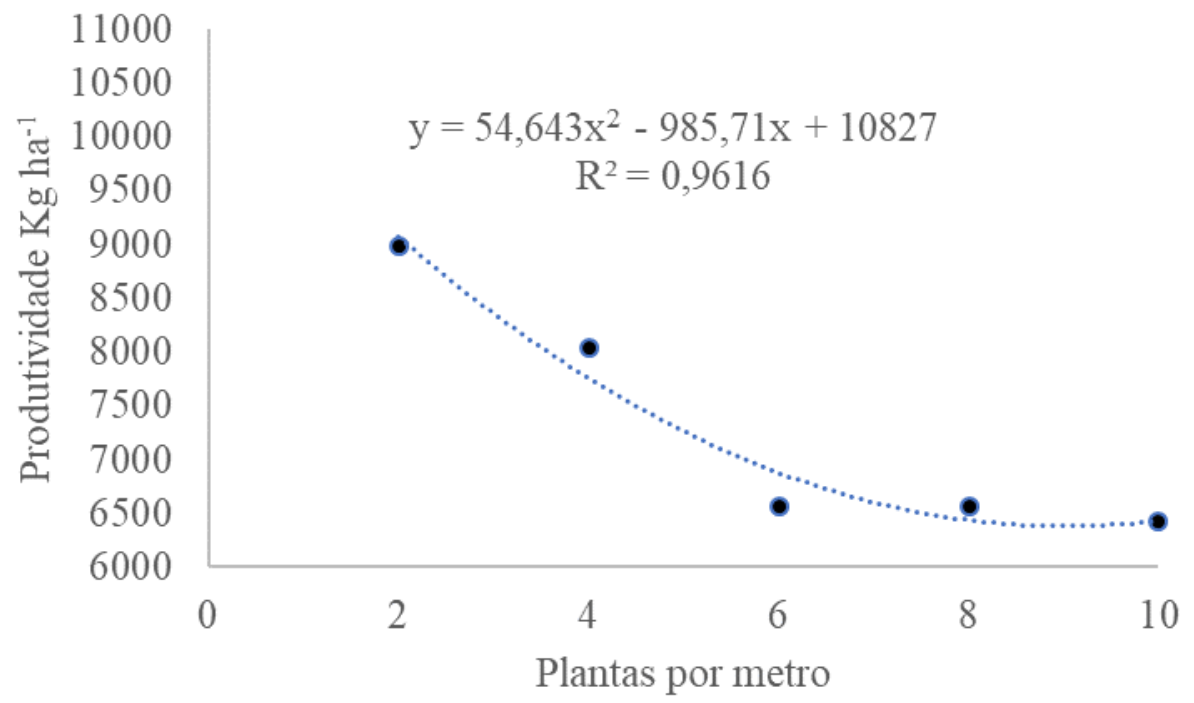

Figura 2A

Fonte: Dados da pesquisa, 2018.

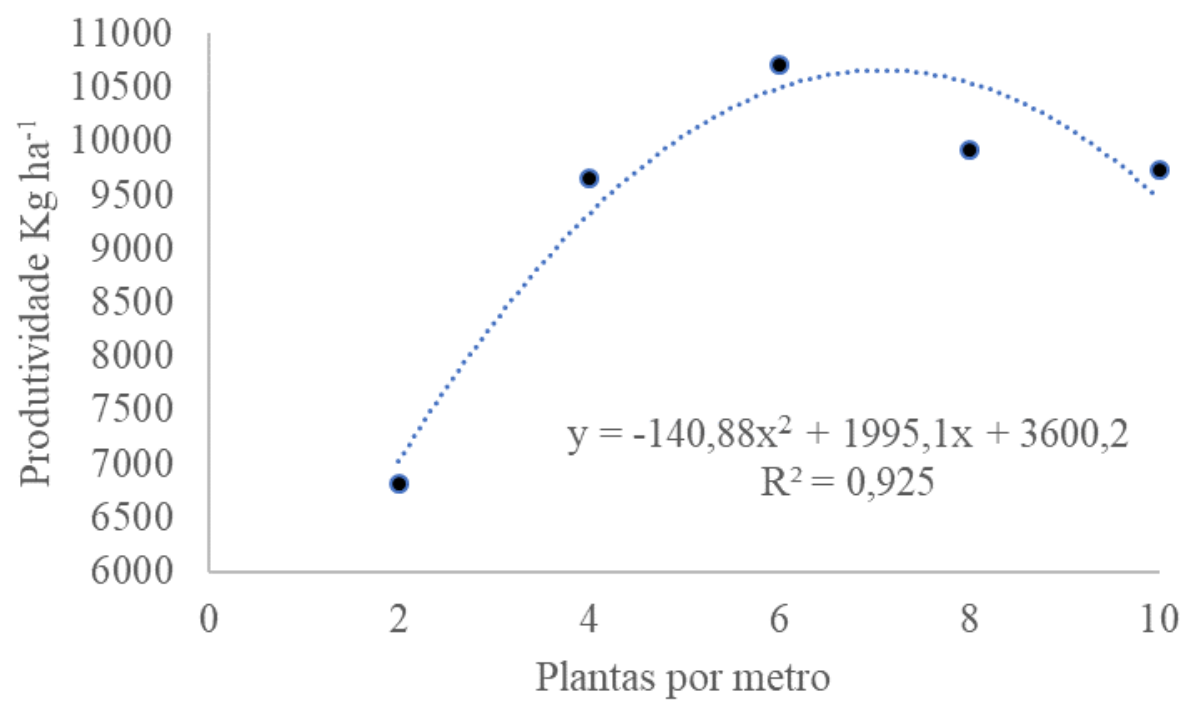

Figura 2B

Fonte: Dados da pesquisa, 2018.

Observa-se na Figura 3A que a curva polinomial para variável tecnologica altura de plantas, ocorreu relação entre os valores de população de plantas e a altura de plantas. Na população de 222.222 plantas por hectare a altura média de plantas encontrada foi de 2,31 metros. O oposto foi registrado para uma menor população em que, 54.444 plantas por hectare, apresentaram uma altura média de 2,05 metros. $\mathrm{O}$ mesmo fato ocorreu no experimento conduzido na segunda safra de 2017/2018 (Figura 3B), onde ocorreu relação entre os valores de população 
de plantas e a altura de plantas. Na população de 210.442 plantas por hectare a altura média de plantas encontrada foi de 2,18 metros. O oposto foi registrado para uma menor população em que, 54.444 plantas por hectare, apresentaram uma altura média de 1,98 metros.

Dados semelhantes foram encontrados por Lima, et al. (2016), em experimento com híbrido P3050 em espaçamento 0,7m. À medida que aumentou a população de 40.000 plantas por hectare para 80.000 plantas por hectare, aumentou também a altura de plantas de 2,74m para 2,77m, respectivamente. Em mesmo trabalho, na população de 20.000 plantas por hectare, 2,12m foi a média de altura de plantas, enquanto para a população maior, 80.000 plantas por hectare foi de $2,30 \mathrm{~m}$. Em espaçamento de $0,7 \mathrm{~m}$ à medida que aumentou a população de 40.000 plantas ha $^{-1}$ para 80.000 plantas ha $^{-1}$ aumentou a altura de inserção da espiga de $1,38 \mathrm{~m}$ para $1,42 \mathrm{~m}$ no híbrido P30R50. Os autores admitem que o maior espaçamento permitiu que as plantas crescessem mais e com o aumento da altura, as espigas puderam inserir em pontos mais altos (Lima, et al. 2016).

Resultados semelhantes foram obtidos neste trabalho, com exceção da maior população testada que foi de 222.220 plantas $\mathrm{ha}^{-1}$ onde a altura de inserção da primeira espiga foi de 1,1 metros. Isto pode ter ocorrido em virtude da variedade de milho ter emitido duas espigas por planta para alguns pés.

Figura 3. Curva polinomial para variável tecnológica altura de plantas submetidas a cinco populações de plantas do híbrido de milho DKB 390 PRO, em segunda safra 2016/2017 (Figura 3A) e 2017/2018 (Figura 3B) na área experimental do Núcleo de Estudo e Pesquisa em Fitotecnia. Município de Mineiros/GO. 2018.

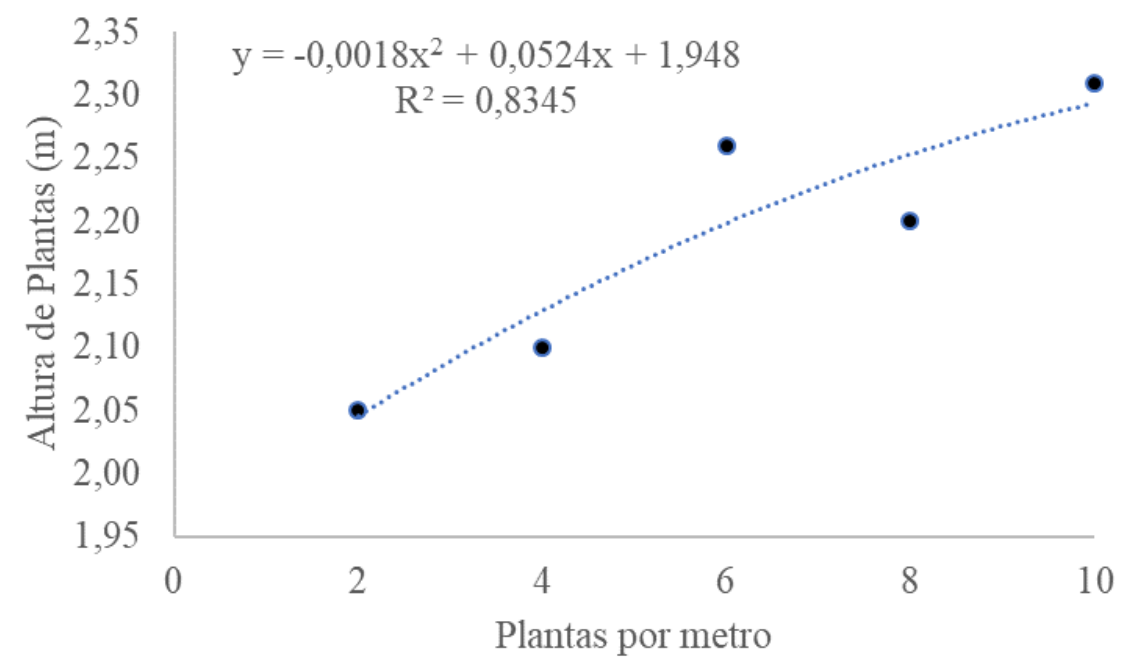

Figura 3A

Fonte: Dados da pesquisa, 2018. 


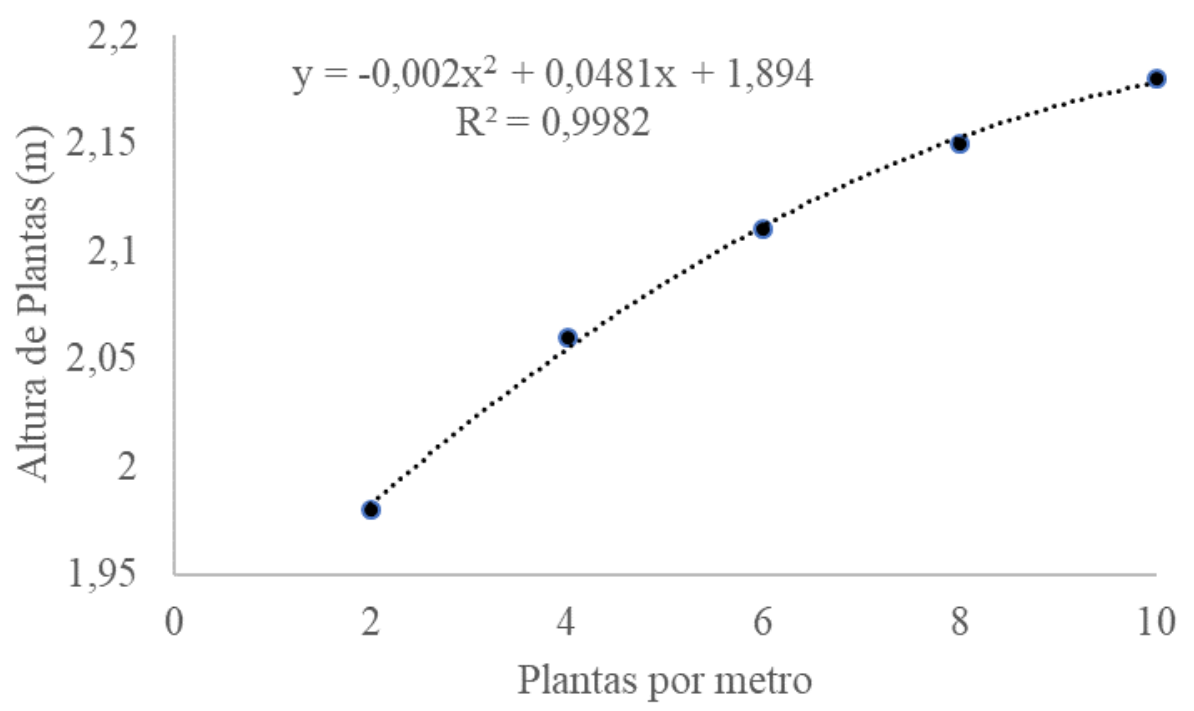

Figura 3B

Fonte: Dados da pesquisa, 2018.

Nota-se na Figura 4 que a curva polinomial para variável tecnologica diâmetro de colmo que a população de 222.220 plantas $\mathrm{ha}^{-1}$ o diâmetro do colmo foi de 15,60 mm, enquanto que na população de 54.444 plantas ha $^{-1}$ foi de $23,24 \mathrm{~mm}$, ou seja, à medida que se aumentou a população, diminuiu o diâmetro do colmo (Figura 4A). Também foi observado no trabalho conduzido em segunda safra de 2017/2018 que a população de 210.442 plantas ha $^{-1}$ o diâmetro do colmo foi de $8,54 \mathrm{~mm}$, enquanto que na população de 45.111 plantas ha $^{-1}$ foi de $16,31 \mathrm{~mm}$, ou seja, à medida que se aumentou a população, diminuiu o diâmetro do colmo (Figura 4B). Esses resultados estão de acordo com Dourado Neto et al., (2003) que relatou que redução da população de plantas, independentemente dos genótipos e espaçamentos utilizados, resulta em aumento no diâmetro do colmo. Segundo Fancelli e Dourado Neto (2003) a competição por luz em plantios densos resulta em plantas maiores e com menor diâmetro de colmo e menor ganho de massa seca. 
Figura 4. Curva polinomial para variável tecnológica diâmetro de colmo em plantas de híbrido de milho DKB 390 PRO submetidas a cinco populações, em segunda safra 2016/2017 (Figura 4A) e 2017/2018 (Figura 4B) na área experimental do Núcleo de Estudo e Pesquisa em Fitotecnia. Município de Mineiros /GO. 2018.

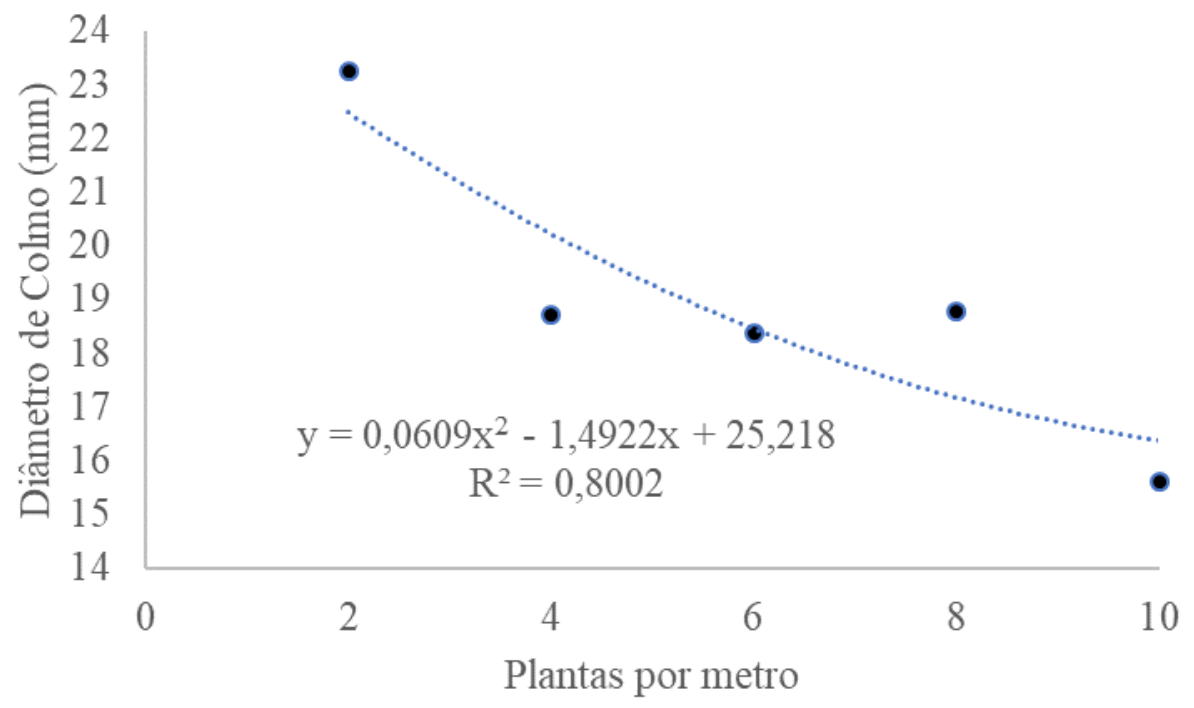

Figura 4A

Fonte: Dados da pesquisa, 2018.

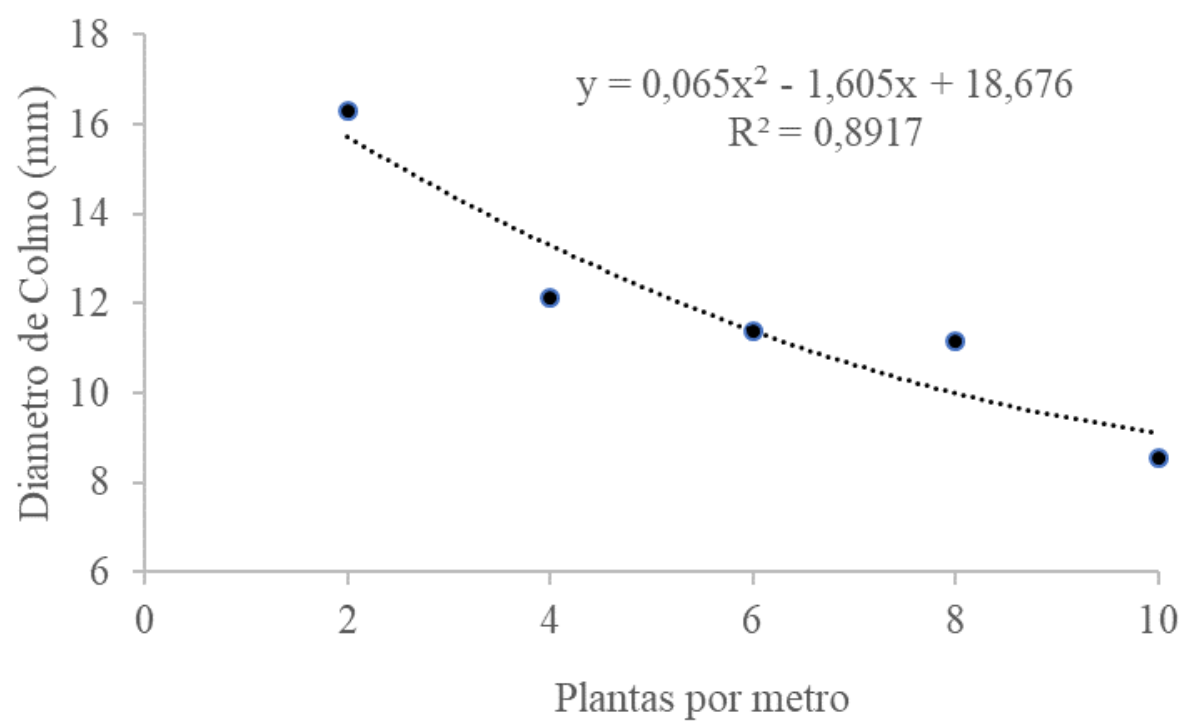

Figura 4B

Fonte: Dados da pesquisa, 2018.

\section{CONCLUSÃO}

A resposta entre a relação população e produtividade no trabalho realizado com a cultura do milho em segunda safra de 2016/2017 mostrou que a produtividade é afetada conforme ocorre o aumento na população de plantas por hectare.

Fato semelhante ocorre no mesmo trabalho realizado na segunda safra de 2017/2018 onde a produtividade também foi afetada conforme ocorre o aumento na população de plantas por hectare. 


\section{AGRADECIMENTOS}

Ao Núcleo de Ensino e Pesquisa em Fitotecnia por contribuir com informações técnicas e cientifica no desenvolvimento destes projetos. A todos os acadêmicos do curso de Engenharia Agronômica pela participação no desenvolvimento deste projeto.

\section{REFERÊNCIAS}

ALMEIDA JÚNIOR, J.J; PEROZINE, A.C; SANTOS, G.A; SMILJANIC, K.B.A; MATOS, F.S.A. Atributos do Solo em Modalidade de Semeadura na Consorciação de Milho com Forrageiras. Nucleus, v.14, n.1, abr. 2017. Disponível em: <http://dx.doi.org/10.3738/1982.2278. 1679> .doi: $10.3738 / 1982.2278 .1679$

BARBOSA, T.G; PORTO, A. P. F; VASCONCELOS, R. C; SOUZA, D. Q; ARAUJO, R. T; ALMEIDA, M. R. S. Efeito da população de plantas sobre características agronômicas de milho em Vitória da Conquista-BA. In: CONGRESSO NACIONAL DE MILHO E SORGO, 28. Anais... 2010. Goiânia: Associação Brasileira de Milho e Sorgo. CD-Rom. Vitória da Conquista - BA.

BULLOCK, D.G.; NIELSEN, R.L.; NYQUIST, W.E. A growth analysis comparison of corn grown in conventional and equidistant plant spacing. Crop Science, Madison, v.28, n. 2, p.254258, 1988. doi:10.2135/ cropsci1988.0011183X002800020015x

BRACHTVOGEL, E. L; PEREIRA, F. R S; CRUZ, S. C. S; ABREU, M. L; BICUDO, S. J; População, arranjo de plantas uniforme e a competição intraespecífica em milho. Revista Trópica - Ciências Agrárias e Biológicas v. 6, n. 1, p. 83, 2012. https://repositorio.unesp.br/bitstream/handle/11449/141177/ISSN1982-4831-2012-06-01-7583.pdf? sequence $=1$; isAllowed $=\mathrm{y}$

CONAB - Companhia Nacional de Abastecimento. Compêndio de Estudos Conab. Sexto levantamento. v. 1, Brasília: Conab, 2017.

CONAB - Companhia Nacional de Abastecimento. Acompanhamento da safra brasileira de grãos. v. 5 - Safra 2017/18, n.9 - Nono levantamento, junho 2018.

DOURADO NETO, D., PALHARES, M., VIEIRA, P. A., MANFRON, P. A, MEDEIROS, S. L. P, ROMANO, M. R. Efeito da população de plantas e do espaçamento sobre a produtividade de milho. Revista Brasileira de Milho e Sorgo, v.2, n.3, p.63-77, 2003.

DOI: http://dx.doi.org/10.18512/1980-6477/rbms.v2n03p\%25p

EMBRAPA - Empresa Brasileira de Pesquisa Agropecuária. Sistema Brasileiro de Classificação de Solos. 3. ed. Brasília, 2013. 353 p.

FANCELLI, A. L. Cultivo racional e sustentável requer maior conhecimento sobre planta do milho. In: Visão Agrícola. USP, ESALQ.Ano 9, julho a dezembro de 2015. ISSN 1806-6402 Disponível em: http://www.esalq.usp.br/visaoagricola/sites/default/files/Esalq-VA13Milho.pdfAcessado em: 20 de outubro de 2018. 
FOLONI, J. S. S; CALONEGO, J. C; CATUCHI, T. A; BELLEGGIA, N. A; TIRITAN, C. S; BARBOSA, A. M. Cultivares de Milho em Diferentes Populações de Plantas com Espaçamento Reduzido na Safrinha. Revista Brasileira de Milho e Sorgo, v.13, n.3, p. 312-325, 2014. http://dx.doi.org/10.18512/1980-6477/rbms.v13n3p312-325

HANASHIRO R. K; MINGOTTE F. L. C; FORNASIERI Filho D. Desempenho fenológico, morfológico e agronômico de cultivares de milho em Jaboticabal-SP. Científica, v12. p. 58, 59. 2015.

HOTZ, D; MASIERO, F. C; VEIGA, R. K; GOEDE, M; IELER, J; Avaliação de diferentes densidades de semeadura na cultura do milho na região do alto vale do Itajaí. IFC-Instituto Federal Catarinense - Campus Rio do Sul. 2015.

KÖPPEN, G; ALVARES, C.A; STAPE, J.L; SENTELHAS, P.C; DE GONÇALVES, M; LEONARDO, J; GERD, S; Köppen's ClimateClassification Map for Brazil. (em inglês). Meteorologische Zeitschrift, 2013. P.711-728.

LIMA, S. F; ALVAREZ, R. C. F; CONTARDI, L. M; Influencia do Espaçamento entre linhas em Características Fitotécnicas e Acúmulo de Massa Seca de híbridos de Milho. Ambiência Guarapuava (PR) v. 12 n. 4 p. 1027- 1039 set./dez. 2016. ISSN 2175 - 9405 DOI: 10.5935/AMBIENCIA.2016.04.NT2.

OLIVEIRA, J. P. P. Influência da densidade populacional na fenologia e na produtividade da cultura do milho. Dissertação (Mestrado Profissional em Agricultura de Precisão). Universidade Federal de Santa Maria - UFSM. Santa Maria, RS, 2014. Disponível em:

http://w3.ufsm.br/ppgap/images/dissertacoes/2014/Juan-Paulo-Padilha-de-Oliveira.pdf

Acessado em: 26 de novembro de 2018.

PINOTTI, E. B. Avaliação de cultivares de milho em função de populações de plantas e épocas de semeadura. Tese (Doutorado em Agronomia). Faculdade de Ciências Agronômicas da UNESP - Campus de Botucatu. Botucatu, 2013. Disponível em: http://www.pg.fca.unesp.br/Teses/PDFs/Arq0931.pdf Acessado em: 26 nov. 2018.

RAIJ, B. VAN; QUAGGIO, J.A. Métodos de Análise de Solo para Fins de Fertilidade. Campinas, Instituto Agronômico, 1983. 31p. (Boletim técnico, 81).

SANTOS, J.F; GRANGEIRO, J.I. T.; BRITO, L. de M.P. OLIVEIRA, M.E.C. Avaliação de cultivares e híbridos de milho para microrregião de Campina Grande, PB Tecnologia e Ciência agropecuária, João Pessoa, v.6, n.2, p. 29-33, jun./2012.

SILVA, F de A.S; AZEVEDO, C.A.V. de. The Assistat Software Version 7.7 and its use in the analysis of experimental data. Afr. J. Agric. Res, v. 11, n.39, p.3733-3740, 2016. 